\title{
Nuevas obras del pintor Cristóbal de Colmenares. La asimilación de las novedades berruguetescas en la Diócesis de León
}

Irune Fiz Fuertes

RESUMEN. Cristobal de Colmenares es un pintor del siglo XVI cuya obra se localiza en la antigua Diócesis de León. Su estilo se caracteriza por la influencia del manierismo berruguetesco. En el presente artículo se le atribuyen diversos retablos a partir del estudio de su única obra documentada, el retablo de la parroquia de Joara.

Palabras clave: Cristóbal de Colemnares, Diócesis de León, Berruguete, siglo XVI, pintura

ABSTRACT. Cristobal de Colmenares is a sixteenth-century painter whose work is located in the old diocese of León. His style is characterised by the influence of Alonso Berruguete. In this article several altarpieces are attributed to him on the basis of the study of his only documented work, the altarpiece of the parrish of Joara.

Key words: Cristóbal de Colemnares, Leon' s Diocese, Berruguete, XVI cebtury, painting.

Dentro del oscuro panorama que todavía presenta la pintura castellano-leonesa del siglo XVI, el caso de León es uno de los que menos progresos ha experimentado en su estudio. Esta situación no se ha producido por la falta de ejemplos pictóricos que hayan llegado hasta nuestros días (Gómez Moreno reseñó en su Catálogo cerca de cincuenta retablos de pincel diseminados por toda la provincia de León ${ }^{1}$, y su estudio no fue exhaustivo), sino que quizá se ha valorado poco su calidad en comparación con otros focos más potentes como Palencia o Zamora. La vinculación con esta última provincia es inevitable a la hora de hablar

${ }^{1}$ M. Gómez Moreno, Catálogo Monumental de la provincia de León. Madrid, 1925. de pintores como el aún anónimo Maestro de Astorga y su círculo, o de uno de los artistas que forman la personalidad estilística del Maestro de Pozuelo, Lorenzo de Ávila, quien residió en la ciudad de León al menos entre 1521 y 1524². Así, los estudios dedicados a León se han unido casi siempre a los de Zamora; tal es el caso de los clásicos trabajos de Post y de Angulo. Ya en fechas más cercanas a nosotros, el estudio de Rodicio, dedicado sobre todo a la compilación de datos aparecidos con anterioridad sobre la pintura del siglo XVI en la diócesis

2 D. DE LOS RIOS, La catedral de León, 1895 t.. I, p. 125 y t.. II, p. 218. E. DÍAZ-JimÉNEZ Y MOLLEDA, “Datos para la Historia del Arte español" Revista de Archivos, Bibliotecas y Museos, t. XLV, (1924), p. 125 
de León, es la única monografía a propósito de este asunto que podemos encontrar ${ }^{3}$. Conviene recordar que la actual provincia leonesa se encuentra dividida en dos diócesis, la de Astorga y la de León. La primera también comprende municipios pertenecientes a Orense y a Zamora; la segunda se extendía en el siglo XVI por varias localidades de Valladolid, Zamora y Palencia. Hay que tener en cuenta estas características a la hora de establecer un área de actuación de los artistas, ya que es bien sabido que éstos solían trabajar bajo la demarcación diocesana.

El artista objeto de este estudio, Cristóbal de Colmenares, trabajó en exclusiva para la diócesis leonesa, o al menos así se desprende de la documentación y las obras conservadas. Sólo contamos con una obra documentada, el retablo mayor de la iglesia parroquial de San Andrés de Joara (León); a partir de esta obra se han atribuido otras como el retablo mayor de la iglesia parroquial de La Antigua (León) ${ }^{4}$. Conocemos además algunos datos de su vida entre 1541, fecha de la contratación del retablo de Joara, y 1563, cuando se le ordena por parte del consistorio leonés devolver, sin que sepamos la causa, 200.000 maravedís $^{5}$.

Su estilo obedece a las directrices marcadas en el segundo tercio de siglo por el manierismo introducido en la península por Alonso Berruguete. De él toma rasgos como los cabellos flotantes al viento de algunos de sus personajes, llenos de dinamismo y muy expresivos, en los que concentra la atención en detrimento del tratamiento pormenorizado del paisaje, más propio de la pintura flamenca. También se interesa por los fuertes contrastes lumínicos

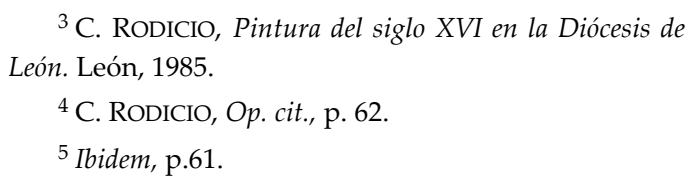

${ }^{3}$ C. RoDICIO, Pintura del siglo XVI en la Diócesis de León. León, 1985.

${ }^{4}$ C. Rodicio, Op. cit., p. 62.

${ }^{5}$ Ibidem, p.61.

y los ambientes con luz crepuscular. Por eso podemos establecer conexiones entre su obra y la de dos de los artistas identificados más influenciados por Berruguete: Luis del Castillo y Juan de Villoldo. Sobre todo con el primero guarda mucha relación estilística y no hay que descartar un posible contacto entre ellos.

Nos hallamos, pues, ante tres artistas coetáneos que trabajan en distintas zonas de Tierra de Campos. Como tantos otros seguidores de las novedades quinientistas introducidas por Berruguete, interpretan éstas con mayor o menor fortuna. Cristóbal de Colmenares es un pintor de inferior calidad frente a los otros dos mencionados. Villloldo se formó con Berruguete ${ }^{6} \mathrm{y}$ Luis del Castillo probablemente con Juan de Soreda $^{7}$. Seguramente Colmenares aprendiera su oficio de un pintor local, a esto se une que León no era un centro puntero del Renacimiento, por lo que su obra es más arcaica y menos correcta. Cuando introduce escorzos para dotar a sus escenas de un mayor dinamismo, éstos se resuelven con torpeza. Existe un deseo de individualizar rostros, pero son casi todos variaciones sobre uno o dos tipos muy reconocibles por su aspecto cerúleo, los ojos pequeños y muy hundidos en la cara. En cuanto a la representación del cuerpo humano, hay un interés por mostrar la anatomía, las figuras son alargadas y corpulentas, con una pequeña cabeza en relación con su masa corporal, lo que se traduce en un aspecto desgarbado, sobre todo si se trata de escorzos, pues las posturas frontales las resuelve menos torpemente; baste comparar dos desnudos, el cuerpo crucificado de San Andrés y el del

\footnotetext{
-

6 J. PARRAdo del Olmo, “Juan de Villoldo", Jornadas sobre el Renacimiento en la provincia de Palencia, Palencia, 1987, p. 61-62.

${ }^{7}$ J. Navarro Talegón, "Pintores en Toro en el siglo XVI" en Pintura en Toro. Obras restauradas, 1985, p. 15.
} 
joven resucitado por San Andrés, ambos del retablo mayor de la iglesia parroquial de Joara.

Basándonos en este retablo, único trabajo documentada de Cristóbal de Colmenares, queremos añadir tres obras más a su catálogo: el retablo mayor de la iglesia de Rabanal de los Caballeros (Palencia), el de la ermita de la Virgen del Socastro en Villamayor de Campos (Zamora) y el de la parroquia de Nuestra Señora de las Nieves en Vega de Infanzones (León). Estas tres localidades pertenecían en el siglo XVI a la diócesis de León.

En el Museo Diocesano de Palencia se conserva un retablo de pincel dedicado a San Martín proveniente de Rabanal de los Caballeros. En el Catálogo Monumental de principios de siglo no se nombra este pueblo, y ya en el Inventario se cita la iglesia de San Martín derruida ${ }^{8}$. El primer libro de fábrica y visitas que se conserva de dicha iglesia comienza en el año de 1598, demasiado tardío para poder darnos el nombre del pintor que realizó el retablo, pues el estilo de las tablas las encuadra a mediados de siglo.

Sin embargo dicho libro empieza con un exhaustivo inventario en el que se cita este retablo que, aunque no se precisa su ubicación, ocuparía el altar mayor por estar sus tablas protagonizadas por la historia del santo titular de la parroquia ${ }^{9}$. Al no especificarse el número de tablas, hay que considerar que en origen estuviera formado por un mayor número de pinturas, completándose así el ciclo iconográfico de San

\footnotetext{
${ }^{8}$ J.J. MARTín GONZÁlez (dir.), Inventario de Palencia y su provincia, t.II, Madrid, 1980, p.153.

${ }^{9}$ Archivo Diocesano de Palencia, libro de fabrica de la parroquia de Rabanal de los Caballeros, fol. 1 "Primeramente un retablo con su custodia y advocación de Sant Martín de talla sobre dorado todo de pincel".
}

Martín, del cual no se han representado todos los pasajes más populares de su vida: únicamente tenemos cuatro tablas en un retablo que consta de tres calles y dos cuerpos, nos parece una obra muy pobre para un altar mayor, además de tener unas medidas desproporcionadas entre su altura y su anchura como para no sospechar que falta al menos un cuerpo más.

La calle central se dedica a la escultura, y en el cuerpo más alto de dicha calle, se sitúa una escultura de bulto redondo con el pasaje más representado de la historia de San Martín: el momento en el que éste comparte su capa con un mendigo comenzando de este modo su leyenda piadosa. Las cuatro tablas de las que consta el retablo, se localizan en las calles laterales y están dedicadas a narrar otros episodios menos conocidos de la vida del santo, extraídos de la Leyenda Dorada de Jacopo della Voragine. El pasaje más temprano de su vida es el de la tabla superior derecha, que representa el momento en el que San Hilario obispo de Poitiers, le nombra su acólito tras abandonar el ejército romano (Fig. 1). Martín aparece arrodillado al lado de la pila bautismal aún como un joven imberbe, vestido como un caballero a la moda del siglo XVI y no como un soldado romano. En las tres escenas restantes lo encontraremos ya vestido de obispo, aunque esto no se corresponda con la narración de la $L e$ yenda Dorada; la siguiente escena es la que se encuentra debajo de la que acabamos de describir, refiere el momento en que San Martín es asaltado por unos ladrones cuando cruzaba los Alpes. En la Leyenda Dorada se nos cuenta este episodio antes de que Martín sea ordenado obispo, sin embargo aquí lo vemos vestido con los ornamentos episcopales $^{10}$. La escena representada en el

\footnotetext{
10 También podría hacer referencia a otro episodio de la vida del santo, ya consagrado obispo, pero vestido humildemente con una capa negra, topa con unos
} 
cuerpo inferior derecho hace referencia al momento en que Martín es consagrado obispo de Tours. El artista no ha incidido en los aspectos anecdóticos. Sitúa la escena en el interior de un templo y dispone las figuras simétricamente en torno a un eje central marcado por la figura sedente del santo. Finalmente, la cuarta tabla relata la última de las tres resurrecciones descritas en la Leyenda Dorada: tras escuchar las súplicas de una madre, San Martín devuelve a la vida a su hijo delante de una muchedumbre que se convierte al presenciar el milagro (Fig. 2). Desde el punto de vista iconográfico, esta tabla es interesante ya que en la figura del resucitado el pintor ha copiado la de Adán en la Creación en el techo de Miguel Angel en la Capilla Sixtina.

El estilo de estas pinturas coincide plenamente con el de la obra de Cristóbal de Colmenares; no es extraño encontrarle en tierras palentinas puesto que Rabanal perteneció a la diócesis de León hasta la reforma de 1955. Lo incluimos en el catálogo de Colmenares por la comparación de tipos con el retablo de Joara, como el San Andrés y el hombre barbado que aparece detrás de San Martín en la escena en que San Hilario le nombra su ayudante. Los rostros de las mujeres, triangulares bajo las tocas, también se repiten, como el de la madre del resucitado por el obispo y la Virgen del Camino del Calvario en Joara, así como los escorzos y el gusto por mostrar anatomías musculadas, aunque sea torpemente proporcionadas, como la figura del resucitado por San Martín y la de los resucitados por San Andrés en el retablo de Joara

soldados cuyas cabalgaduras se asustaron ante el aspecto del santo, los soldados, enfurecidos, le dieron una paliza que él aguantó mansamente. En la pintura que nos ocupa vemos soldados y civiles sujetando al santo, lo cual induce a error, lo mismo que el hecho de que se encuentre maniatado, tal y como se refiere en el tropiezo con los ladrones, por lo que probablemente el artista haya combinado partes de los dos encuentros.
(Fig. 3). También el tratamiento del espacio coincide en ambos casos. La sensación de agobio espacial, sobre todo en las escenas de interior, en las que se manifiesta la torpeza en la construcción de la caja escénica, con las paredes laterales y el techo muy inclinados; el suelo se abate demasiado hacia el espectador, la desproporción entre las figuras y la arquitectura que las enmarca es así mismo evidente en ambos retablos. Otra característica común es el empleo del color. Como ya se ha señalado, el pintor da un aspecto cerúleo a los rostros y cuerpos de sus personajes, en contraste con las vestiduras de tonos más vivos, con una preferencia por los rojos y amarillos. El ambiente de la composición en general es oscuro pero con una luminosidad que parece sobrenatural como en las obras de Villoldo y de Berruguete. Coincide además con estos dos pintores en ambos retablos en la concentración en la escena narrativa dejando de lado el anecdotismo y detallismo propio de la etapa anterior, herencia de la pintura flamenca; de este modo, no se entretiene en la pormenorización del paisaje.

La segunda obra que vamos a tratar se encuentra en la localidad zamorana de Villamayor de Campos. Antiguamente perteneció a la diócesis de León, de ahí su vinculación con la pintura leonesa. Es el retablo mayor de la ermita de la Virgen del Socastro ${ }^{11}$. El retablo, muy sencillo, de traza moderna, consta de siete tablas, dos de ellas en el banco con las parejas de apóstoles de San Andrés y Santiago, San Pablo y San Pedro, y las cinco restantes, Crucifixión, Lamentación ante Cristo muerto, Resurrección, Asunción y Natividad, distribuidas sin guardar orden cronológico en el cuerpo del retablo.

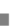

${ }^{11}$ D. DE las Heras HernándeZ, Catálogo artístico monumental y arqueológico de la diócesis de Zamora. Zamora, 1973 p. 192, nos informa de que esta denominación proviene de la latina sub castrum romanum, un castro romano arrasado por los musulmanes.
} 
De nuevo, la comparación estilística nos lleva a afirmar que este retablo fue hecho por Cristóbal de Colmenares. Baste comparar la Lamentación y los apóstoles del banco (Fig. 4) con las tablas del mismo tema en Joara (Fig. 5). Es precisamente esta comparación de ambos retablos la que nos permite observar una menor calidad del retablo de Villamayor, sobre todo en la Resurrección y la Natividad. No obstante, no se trata sólo de la mera repetición de composiciones por parte de imitador, sino que probablemente su menor calidad es debida a la intervención del taller del pintor.

La parroquia de la localidad leonesa de Vega de Infanzones es de reciente construcción, pero el retablo de pincel que ocupa el presbiterio es del siglo XVI, y algunas de sus tablas fueron hechas por Cristóbal de Colmenares. El retablo se distribuye en tres cuerpos y cinco calles, la central reservada a escultura menos en el último cuerpo, donde se localiza una tabla representando el Calvario. Como es frecuente, el primer cuerpo se dedica a los apóstoles, con cuatro tablas en las que aparecen tres en cada una. Las tablas del segundo y tercer cuerpo, dedicadas a la representación de pasajes de la vida de la Virgen y de Jesucristo, no guardan un orden secuencial lógico, ya que, leyendo el retablo de abajo a arriba y de izquierda a derecha, empezamos con la Asunción, el Bautismo de Cristo, Jesús entre los doctores y la Dormición de la Virgen en el segundo cuerpo, y en el tercero y último, la Purificación, Epifanía, Crucifixión, Natividad y Huida a Egipto. Salvo en la predella, que tiene un estilo unitario, en el resto de las tablas observamos la intervención de dos pintores: unas tienen soluciones compositivas ancladas en los modelos provenientes del Quattrocento italiano, empleados por los pintores castellano-leoneses hasta la renovación que supuso la pintura de Alonso Berruguete; el resto de las tablas, más avanzadas, serían obra de Cristóbal de Colmenares, con las características ya rese- ñadas de imitación de la maniera introducida por Berruguete. En el primer grupo incluimos el Bautismo (Fig. 6), la Purificación, Nacimiento y Huida a Egipto. El resto, incluido el banco, se debe a Cristóbal de Colmenares, aunque quizá en la Epifanía pudo haber intervenido otro pintor, ya que no concuerda plenamente con su estilo. Volvemos a encontrar en las tablas que le atribuimos rasgos singulares que identifican el estilo de este pintor, como el agobio espacial, los gama de los vivos colores empleados en fuerte contraste con los fondos poco detallados y en colores neutros, los ascéticos rostros que parecen de cera y las anatomías de canon alargado y un tanto desproporcionado, sobre todo por la frecuente utilización del escorzo. Pensamos que se trata de una obra más madura que la del retablo de Joara, ya que maneja más resueltamente los medios del nuevo lenguaje, por ejemplo, en Jesús entre los doctores (Fig. 7) o en la Dormición de la Virgen. El agobio espacial ya no parece fruto de la torpeza, sino un recurso expresivo: las figuras ya no parecen agolpadas pese a la escasez de espacio, se abandona la isocefalia y algunos vestigios de perspectiva jerárquica que se encuentran en Joara y cada personaje está dotado de individualidad tanto en el rostro como en las posturas.

Vistas las tablas de estos tres retablos de los que nos parece segura la paternidad de Cristóbal de Colmenares, queremos dejar breve constancia de otras obras que se pueden relacionar con un retablo atribuido a Colmenares, el de la parroquia de La Antigua en León ${ }^{12}$. Habría que empezar por estudiar a fondo este último retablo, cuyo lamentable estado, con las tablas sucias y llenas de repintes, dificulta su asignación. Pese a su deterioro, al comparar sus pinturas con las del documentado retablo de Joara, es innegable en alguna de ellas su

${ }^{12}$ C. Rodicio, Op. cit., p. 62. 
filiación con la obra de Colmenares, como el Anuncio del ángel a San Joaquín (Fig. 8), Visitación, Adoración de los pastores, Oración en el huerto, Calvario ó Piedad (Fig. 8), pero también es evidente que hay algunas tablas en las que se utiliza un canon más achaparrado que el utilizado por Colmenares, una composición más rígida, más arcaica, buscando el equilibrio compositivo y tonal ${ }^{13}$; de este grupo nos parecen el Anuncio del ángel a Santa Ana, Abrazo ante la Puerta Dorada, Anunciación, Asunción y todo el apostolado. Estos mismos rasgos retardatarios los encontramos en los retablos de otras dos localidades pertenecientes a la provincia de León, Villarrabines y Fuentes de Carbajal.

El primero en el que nos vamos a detener ocupó el retablo mayor de la parroquia de San Cipriano en Fuentes de Carbajal. Relata la vida San Cipriano de Antioquía. De las dieciocho tablas de las que consta el retablo, cuatro se dedican a narrar su historia: la visita de los demonios en el estudio de San Cipriano, la conversión de San Cipriano, el martirio de éste y de Santa Justina, al ser introducidos en un caldero de pez hirviente y la decapitación de ambos, ya que resistieron el suplicio anterior. El resto de las pinturas se consagran a la Infancia de Cristo y a su Pasión. El banco se reserva a la representación de ocho apóstoles y en último cuerpo se situaba Santiago Matamoros. Desde 1972 se encuentra en el Museo Diocesano de León ${ }^{14}$, donde están expuestas al

\section{-}

${ }^{13}$ Se podría equiparar al estilo de Lorenzo de Ávila y la escuela de pintura toresana coetánea a esta pintura leonesa; no hay que descartar la influencia directa de esta escuela en los pintores leoneses, ya que además de la estancia de Lorenzo de Ávila en León que hemos apuntado antes, hay varias localidades cercanas a La Antigua con retablos de pincel vinculados al estilo del foco toresano. En todo caso, estas pinturas tiene una calidad inferior y un escaso interés por los fondos paisajísticos tan representativos de la escuela de Toro.

14 J.A. GARCía BOLAÑos, “Las pinturas del retablo de Fuentes de Carbajal", Diario de León, 31-VII-1988 público siete tablas: Anunciación, Natividad, Epifanía, Huida a Egipto, Última Cena, Oración en el Huerto y San Cipriano tentado en su estudio por los Demonios.

Gómez Moreno no pudo verlo, pero pese a ello, lo relaciona con el de Vega de Infanzones, cuyo retablo calificó de "Escuela de Berruguete" ${ }^{15}$. Rodicio le encontró influencia alemana ${ }^{16}$. Con el retablo de La Antigua coincide estilísticamente en la representación de la Anunciación (figs. 9 y 10) y del apostolado, mientras que otros pasajes como la Huida a Egipto, Las tentaciones de San Cipriano ${ }^{17}$ o la Natividad coinciden más con los rasgos atribuidos a Cristóbal de Colmenares, sin que nos atrevamos categóricamente a incluirlo entre su producción; en todo caso se trataría de una obra muy temprana, ya que si bien los rostros se identifican fácilmente con los del retablo de Joara, la composición está todavía poco influida por el manierismo; quizá donde más se advierta la presencia de éste sea en la Huida a Egipto, especialmente en el ángel tan movido que aparece a la derecha de la Virgen (Fig. 11): si lo comparamos con el San Gabriel de la Anunciación, inserto en una rígida composición de herencia quattrocentista, llegamos a la conclusión de que ambos no pueden haber sido hechos por un mismo pintor.

El retablo mayor de la parroquia de Villarrabines se encuentra actualmente en Santa María de Linares (Jaén). Para el presente estudio nos interesa por la plena concordancia de soluciones compositivas de algunas de sus pinturas con las de La Anti-

${ }^{15}$ M. GÓMEZ MORENO, Ob. Cit., pp. 515-516.

${ }^{16}$ C. Rodicio, Op. Cit., p. 28.

17 J. Rivera De LAS HerAs, Las Edades del hombre. El contrapunto y su morada, Salamanca, 1993, ficha no 83, se refiere al hablar de esta tabla en concreto a "contactos con las escuelas de Cristóbal de Colmenares y otros maestros locales atentos a las influencias de Juan de Borgoña y de Juan de Flandes" 
gua y las de Fuentes de Carbajal; por ejemplo, la Anunciación (Fig. 12) coincide con la de ambos retablos, la Epifanía y Presentación de la Virgen con La Antigua, mientras que la Natividad y la Huida a Egipto se corresponden con las mismos temas de Fuentes de Carbajal ${ }^{18}$.

Dudamos de que se trate del mismo autor, pero nos sirve para concluir que, como en el resto de la península, hay una transmisión de las fórmulas compositivas a lo largo de una comarca (Fuentes de Carbajal, La Antigua y Villarrabines son localidades vecinas) sin apenas cambios; esta pintura sufre una transformación con la llegada de Alonso Berruguete, la asimilación y puesta en práctica de sus novedades se llevará a cabo con mayor o menor fortuna en los diferentes focos castellano-leoneses, coexistiendo la implantación de estas fórmulas con las soluciones anteriores, ancladas en la doble influencia de la pintura del Quattrocento italiano y de los primitivos flamencos. Si damos por probable la intervención de Cristóbal de Colmenares en parte del retablo de Fuentes de Carbajal, nos ayuda para tipificar por una parte, la evolución de un pintor desde una tímida

\footnotetext{
${ }^{18}$ El retablo de Villarrabines merece un estudio detallado en el que no vamos a entrar, pero queremos dejar constancia de su existencia fuera de su emplazamiento original y de su importancia, para futuras investigaciones pormenorizadas de la pintura leonesa del siglo XVI. También se aprecia la mano de otro pintor mucho más avanzado que maneja estampas rafaelescas, cuyo estilo es diferente del de Cristóbal de Colmenares. Gómez Moreno relacionó este retablo con la obra de Correa de Vivar y el anónimo de Toro, personalidad estilística esta última que hoy se resume en Lorenzo de Ávila y su escuela; de nuevo sale a relucir la escuela de Toro en torno a la pintura leonesa (aunque Villarrabines pertenecía en el siglo XVI a la diócesis de Oviedo), en este caso no creemos que se trate de una obra que se pueda incluir dentro de las hechas por esta escuela, pero si entran dentro de su ámbito de influencia algunas de las tablas como los Desposorios, el Abrazo ante la Puerta Dorada ó sobre todo San Miguel en el Monte Gárgano y en la Visitación.
}

imitación del lenguaje berruguetesco hasta su pleno entendimiento en el retablo de Vega de Infanzones. Por otra parte ejemplariza la coexistencia de este lenguaje avanzado con otro más retardatario, por las continuas colaboraciones de Colmenares con otros pintores menos aventajados. Así como la pérdida de calidad pese al mantenimiento de un mismo estilo en el retablo de Villamayor de Campos es ejemplo de una tercera característica común a toda la región en el siglo XVI: la existencia de talleres que se limitaban a seguir las directrices del maestro, de lo que se puede deducir el carácter artesanal otorgado a la pintura durante todo el siglo XVI. 

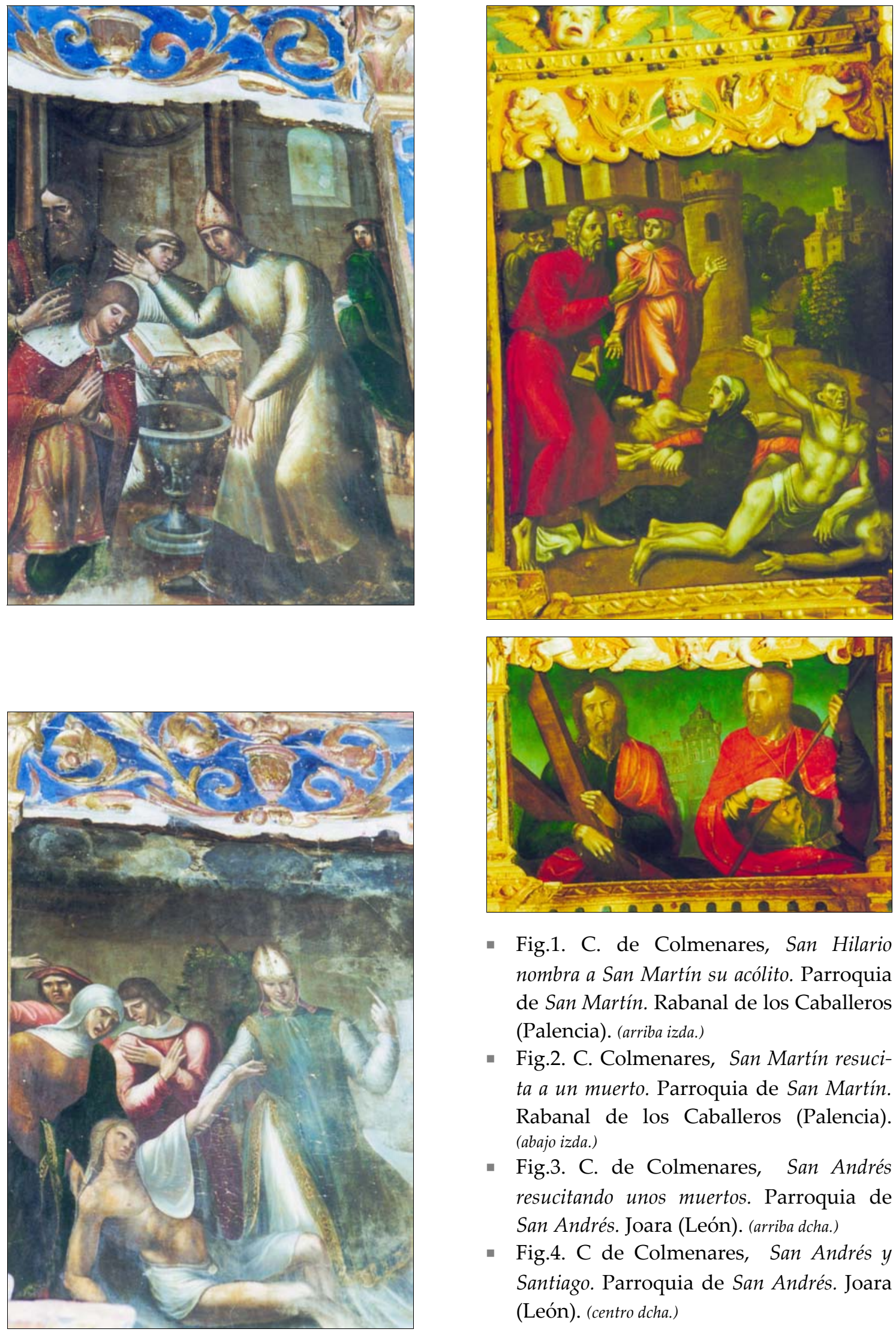

- Fig.1. C. de Colmenares, San Hilario nombra a San Martín su acólito. Parroquia de San Martín. Rabanal de los Caballeros (Palencia). (arriba izda.)

- Fig.2. C. Colmenares, San Martín resucita a un muerto. Parroquia de San Martín. Rabanal de los Caballeros (Palencia). (abajo izda.)

- Fig.3. C. de Colmenares, San Andrés resucitando unos muertos. Parroquia de San Andrés. Joara (León). (arriba dcha.)

- Fig.4. C de Colmenares, San Andrés y Santiago. Parroquia de San Andrés. Joara (León). (centro dcha.) 

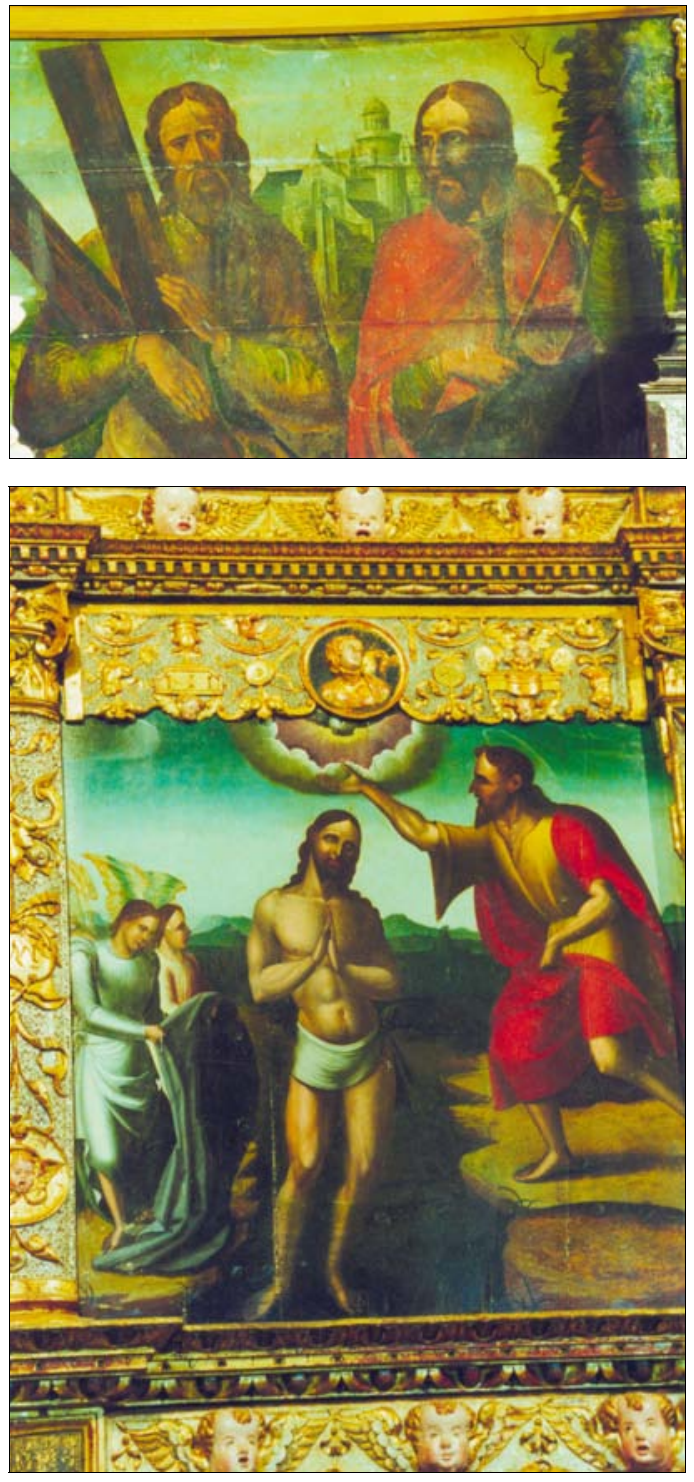

- Fig.5. C. de Colmenares, San Andrés y Santiago. Ermita de la Virgen del Socastro. Villamayor de Campos (Zamora) (arriba izda.)

- Fig.6. Anónimo. Bautismo de Cristo. Parroquia de la Virgen de las Nieves. Vega de Infanzones (León) (centro izda.)

- Fig.7. C. de Colmenares, Jesús entre los doctores. Parroquia de la Virgen de las Nieves. Vega de Infanzones (León) (arriba dcha.)

- Fig.8. C. de Colmenares. Piedad (det.); Anuncio del ángel a San Joaquín (det.). Parroquia de Santa María. La Antigua (León) (abajo dcha.)
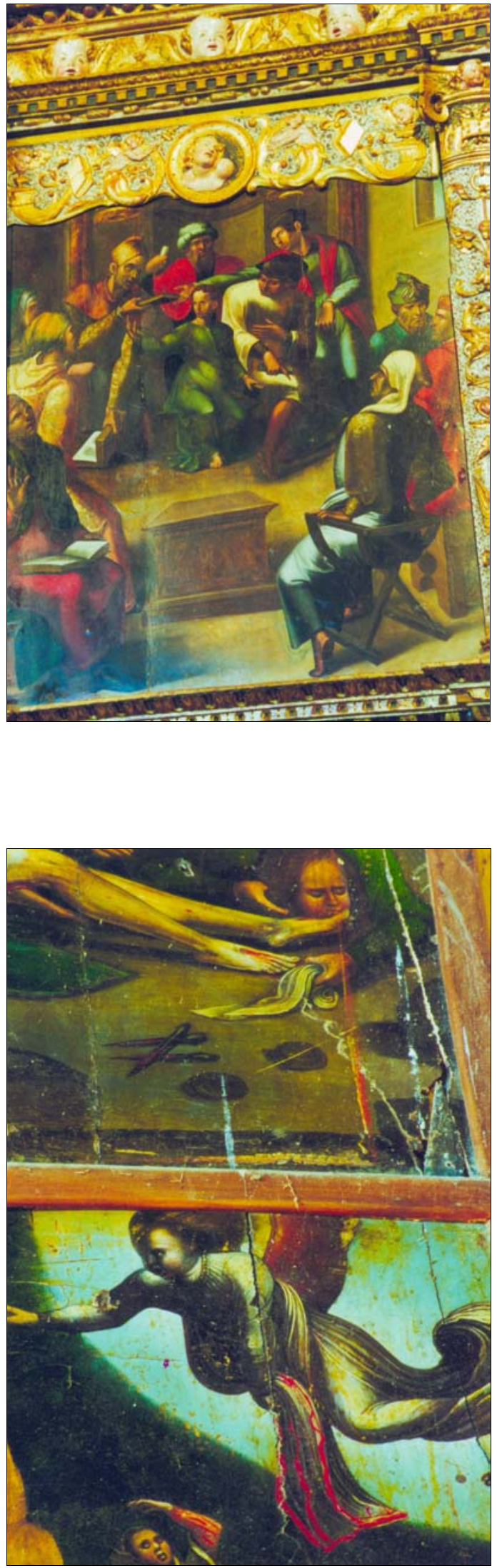

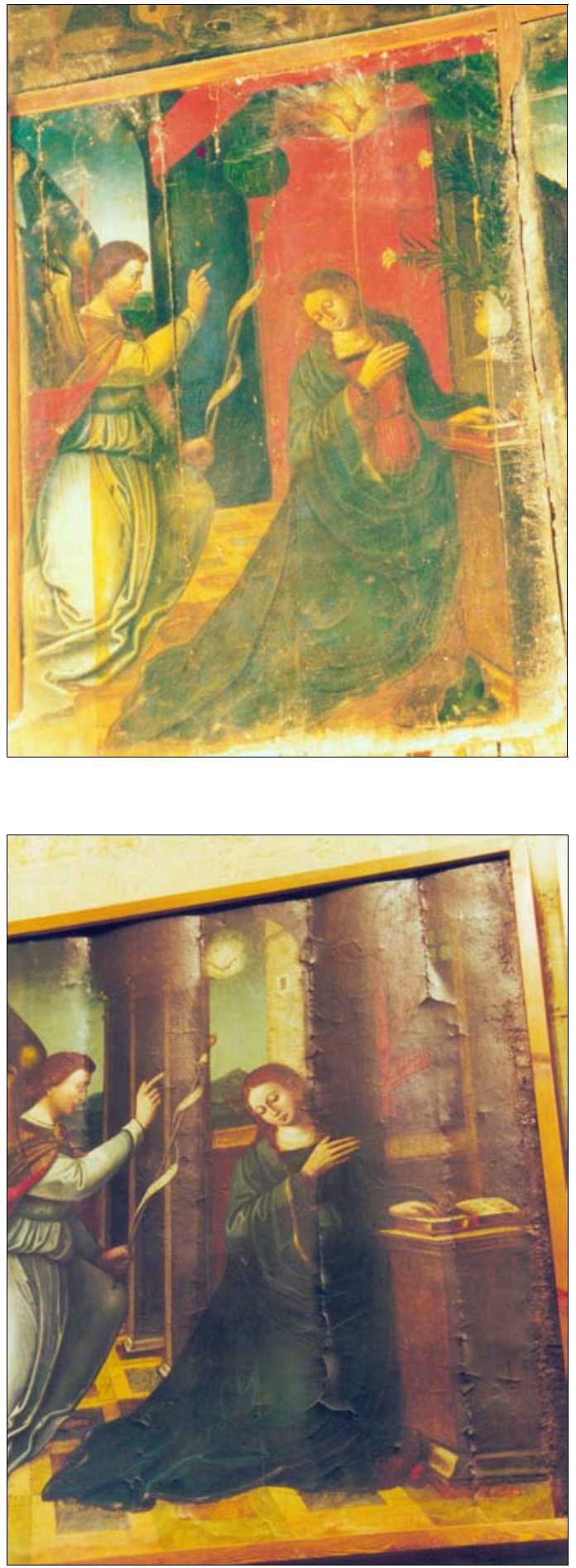

- Fig.9. Anónimo. Anunciación. Parroquia de Santa María. La Antigua (León). (arriba izda.)

- Fig.10. Anónimo. Anunciación. Parroquia San Cipriano. Fuentes de Carbajal (León) (abajo izda.)
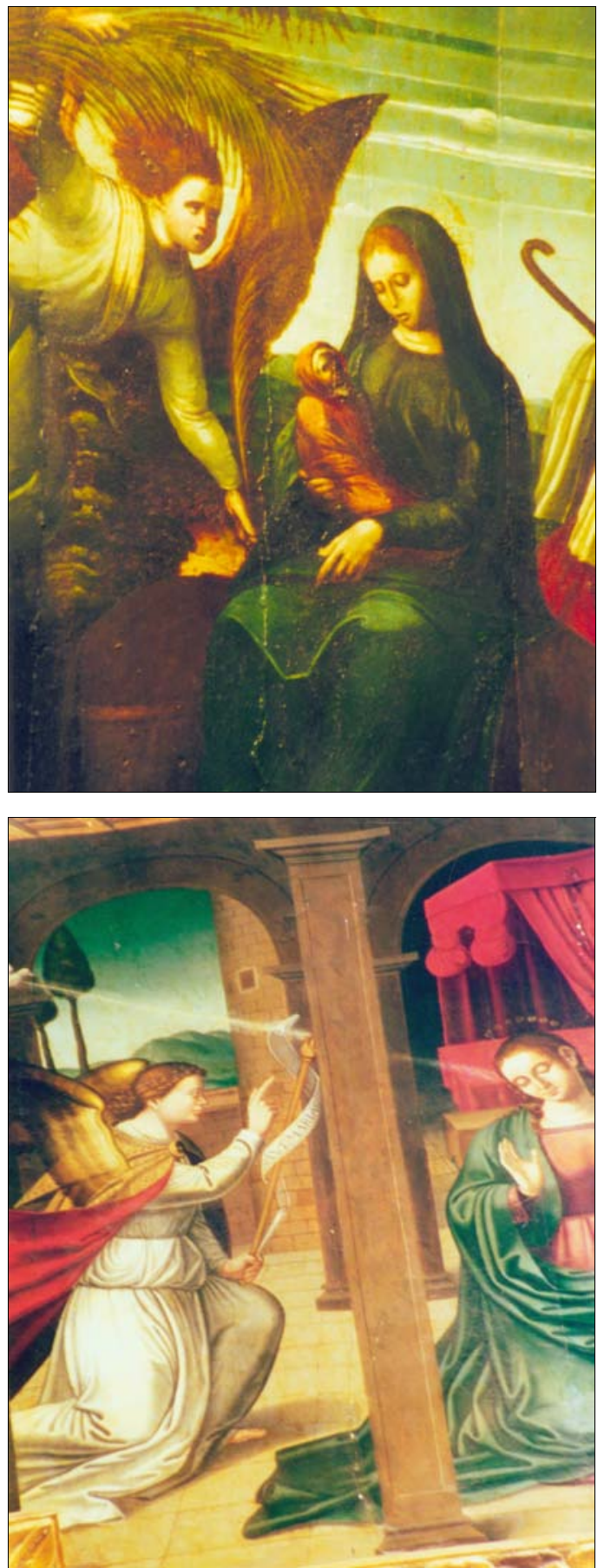

- Fig.11. ¿Cristóbal de Colmenares?. Huida a Egipto (det.). Parroquia San Cipriano. Fuentes de Carbajal (León) (arriba dcha.)

- Fig.12. Anónimo. Anunciación. Parroquia de Sta. $M^{a}$. Villarrabines (León). (abajo dcha.)

(fotos de la autora) 